\title{
Facing up to longevity with old actuarial methods: a comparison of pooled funds and income tontines
}

\author{
Marcel Bräutigam ${ }^{1}$, Montserrat Guillen ${ }^{2}$ and Jens P. Nielsen ${ }^{3}$ \\ ${ }^{1}$ ETH Zurich, Zurich, Swizerland. \\ ${ }^{2}$ Dept. Econometrics, Riskcenter-IREA, University of Barcelona, Spain. \\ ${ }^{3}$ Cass Business School, City University London, United Kingdom.
}

\begin{abstract}
We compare the concepts underlying modern actuarial solutions to pension insurance and present two recently developed pension products - pooled annuity overlay funds (based on actuarial fairness) and equitable income tontines (based on equitability). The two products adopt specific approaches to the management of longevity risk by mutualizing it among participants rather than transferring it completely to the insurer. As the market would appear to be ready for such innovations, our study seeks to establish a general framework for their introduction. We stress that the notion of actuarial fairness, which characterizes pooled annuity overlay funds, enables participants to join and exit the fund at any time. Such freedom of action is a quite remarkable feature and one that cannot be matched by lifelong contracts.
\end{abstract}

Keywords: pensions, lifetable, retirement income, longevity risk, actuarial fairness, equitability

\section{Introduction and motivation}

Annuity providers face systematic longevity risk and are obliged, therefore, to set aside solvency capital and to pay reinsurance premiums. In the current environment of low interest rates this means that annuitants receive lower annuities than they did in the past, which in turn impacts financial decisions for retirement, lowering the overall appetite for annuity projects (see, among others, Lusardi and Mitchell, 2007). Despite the demand from pension providers, the market for longevity risk is limited (see, Lin and Cox, 2005, and Chan et al., 2016, among many others). Given this state of affairs, an interesting new stream has emerged in the academic literature that adopts a different focus to annuities by pooling longevity risk among participating pensioners. Some of these products take their inspiration from ideas similar to those employed by Lorenzo di Tonti in the seventeenth century (see, Milevsky, 2015). A lump sum payment gave the right to an annuity and this lifelong pension increased over time, as the yields were increasingly distributed among a smaller number of surviving beneficiaries. Likewise, modern tontine-type annuity products reduce longevity risk for the companies providing them, and they can therefore be offered to customers at a lower cost (see, Donnelly 2015).

The inception of this new class of pension scheme is receiving, and seems likely to attract much more, attention in the academic literature as well as in the market, with many insurers keen to explore innovations in retirement products. Weinert and Gründl (2016) are in favour of tontinizing some fraction of the individual retirement wealth on the individual lifetime utility, considering an increasing liquidity-need at old ages. 
In this paper we consider a few examples of this new class of pension product and outline some of their respective similarities and differences. In so doing, we show that there are fundamental concepts in the definition of these products that deserve closer attention. A survey of the methods employed and a new general framework for these pension products are fundamental for future developments in this rapidly growing area of pension insurance.

\section{Description}

We analyse pooled annuity overlay funds and equitable retirement income tontines by comparing two recent actuarial approaches to eliminating the longevity risk management constraints of the annuity business. We do so by comparing the respective contributions of Donnelly et al. (2014) and Milevsky and Salisbury (2016). The basic concept underpinning both approaches is the pooling of the wealth of individuals (and, hence, their mortality risk) as opposed to individuals investing separately in the pension products provided by an insurer. Both approaches have a similar starting point insofar as they modify an existing product in order to treat all participants equally.

To formalize this concept of equality, Donnelly et al. (2014) introduced the notion of actuarial fairness, that is, if the expected actuarial gains (i.e., the benefits expected from participating minus the initial investment) are zero and this holds for all participants, then the product is deemed 'actuarially fair'. In other words, no single participant subsidizes or benefits from the other participants. Milevsky and Salisbury (2016) introduced their slightly weaker condition of equitability, that is, if the expected benefits, measured in terms of per dollar of initial investment, are equal for all participants then the product is deemed 'equitable'. By definition, 'fairness' implies 'equitability', since the expected benefits per dollar of initial investment would be equal to exactly one dollar for all participants. However, the reverse implication does not hold. Thus, while equitability means that the expected benefits are equal for all participants, they might still be lower than the initial investment made. Hence, the expected actuarial gain would be less than zero, whereas for fairness to hold the actuarial gain needs to be zero. Below we compare the two potential products based on this reasoning.

\subsection{The pooled annuity overlay fund}

Although Donnelly et al.'s (2014) pooled annuity overlay fund includes the word annuity, the concept is quite distinct from that of a standard life annuity. It does not, for example, transfer the risk of mortality to a third party (insurer), nor does it guarantee the pensioner a fixed payout stream (until death). Yet, it does seek to overcome the problems inherent to a life annuity, including its lack of transparency as regards costs (and, hence, the fairness of the proposed price) and the irreversibility of a lifelong contract, which is its most notable characteristic. The goal of Donnelly et al. (2014) is to propose a new kind of pooled annuity fund that is transparent in its costs, actuarially fair and which guarantees the investment freedom of each individual in addition to the heterogeneity of the group.

Let us begin by examining the pooled annuity fund proposed by Stamos (2008). This product pools the wealth and mortality risk of a homogeneous group of individuals (i.e., same age, same mortality rate and same initial investment). Whenever one of the individuals in the fund dies, their wealth is redistributed among the surviving participants in proportion to their current wealth. Stamos' (2008) contribution is to derive the optimal continuous-time payout structure (or consumption) and the optimal portfolio choice. Donnelly et al. (2014) introduce a 
generalisation of this pooled annuity fund, which they refer to as the pooled annuity overlay fund. The idea can be simply explained: for a specified amount of time, individuals pool their wealth, but if one participant should die during this period their wealth is redistributed among the survivors and the participant that has died (i.e., a part of the money is left as a bequest to his descendants). The amount redistributed to each individual is proportional to the initial wealth invested and their rate of mortality. At the end of the specified period, the pool is dissolved. Note that in theory the pooled annuity overlay fund operates on an instantaneous basis rather than over a long time period. A key feature of the product is that it is actuarially fair at every instant in time (Proposition 3.1 in Donnelly et al., 2014). The advantages of actuarial fairness are manifold: first, it is possible to exit the fund at any given time (given that the expected actuarial gains are zero, an individual can exit the fund simply by withdrawing their money); and, second, no group of individuals profits financially at the expense of another group and so individuals with different demographics can join the pool without any restriction.

As the pooled annuity overlay fund allows individuals to decide how they want to invest their wealth on the financial market, overall financial gains depend on their risk preferences. Donnelly et al. (2014) report extensive numerical simulations to illustrate how the performance of a pooled annuity overlay fund compares to that of a mortality-linked fund (as introduced by Donnelly et al., 2013). The latter is similar in many respects to a pooled annuity fund, insofar as the participants also pool their wealth but in this instance the insurer (or the seller of the product), as opposed to the participants, bears the volatility of mortality. As a result, the participants obtain a deterministic, mortality-linked interest rate (that is proportional to their mortality rate) instead of redistributing the wealth of the deceased participants among the survivors. However, upon their death the participants lose their money (to the fund). While the pooled annuity overlay fund has two sources of volatility (that of the financial market and of mortality), the mortality-linked fund is volatile only as regards the members' investments in the financial market. A comparison of the two products shows that the use of a pooled annuity overlay fund can be advantageous, since for the same volatility as in the mortality-linked fund a higher expected return can be achieved with a moderately heterogeneous pooled annuity overlay fund of just a few hundred members (Donnelly et al., 2014).

\subsection{The income tontine}

The second actuarial product we examine is the optimal retirement income tontine developed by Milevsky and Salisbury (2016). The income tontine is very different from the pooled annuity fund: first, because the value of the lifelong payments made to the group of tontine participants (the payout) is deterministic and, second, because the whole lifecycle has to be considered as the timeframe. However, the product employs a similar idea to the product developed by Donnelly et al. (2014) insofar as it distributes the payout in relation to the individual's wealth and a share price (that usually depends on the mortality rate).

To understand the idea presented by Milevsky and Salisbury (2016), we need to go back and examine the original concept of the tontine annuity, whereby a group of individuals invested the same amount of money in the financial product. In exchange, a regular dividend payout was made to survivors until the last participant died. According to Milevsky and Salisbury (2016), the mechanism can be seen as "a perpetual (i.e., infinite maturity) bond that is purchased from an issuer by a group of investors who agree to share periodic coupons only amongst survivors". Clearly, this classical concept implied a transfer of wealth from the old to the young. Imagine two individuals, one old and one young, investing an equal amount in this 
perpetual bond. As the elder of the two is likely to die first, the expected actuarial gains of the younger individual will be higher than those of the older participant, which makes this agreement actuarially unfair. Milevsky and Salisbury (2016), in contrast, adapt the classical tontine (in a fashion similar to Donnelly et al., 2014, when working with the pooled annuity fund) and introduce equitable tontines, i.e., tontines where all the participants have the same expected benefits.

However, it should be stressed that Milevsky and Salisbury's (2016) setup differs from that of the pooled annuity overlay fund in a variety of ways. First, as stated, they focus solely on lifetime income, which means that the timeframe is fixed to the whole lifecycle. This also means that individuals can neither enter nor exit the equitable tontine once it has been set in motion. Furthermore, modern tontines offer the prospects of a deterministic rule (in special cases near constant) payout in contrast to Donnelly et al.'s (2014) product, while they do not provide the possibility of making a bequest. All the wealth is distributed solely among the surviving participants (i.e., no part of the fund is set aside for recently deceased participants). Finally, in this case the management of the pooled investment is external and, thus, likely to be costly.

\section{Notation and models}

Having briefly introduced the main features of the models, we now describe them more formally. Let us assume we have a group with $n$ participants. We can then split this group into $M$ homogeneous subgroups each with $n_{i}$ participants so that $\sum n_{i}=n$. The homogeneity of these subgroups is reflected in the fact that their members have the same age, wealth, risk preference and mortality characteristics. This means each participant in a subgroup $k$ has the same rate of mortality $\lambda_{t}^{k}$ and wealth $W_{t}^{k}$. Note that this mortality rate and wealth refer to an instant in time t.

In the pooled annuity overlay fund all members of the same subgroup have the same risk preferences with regards to investment, which means that their wealth allocation strategy in response to a riskless and a risky asset is invariable throughout the subgroup. The main question that remains unanswered is how actuarial gains can be accumulated. As this occurs on a continuous basis, let us specify an instant in time $(t, t+d t)$ for this. The wealth of each individual that dies in this short period of time is placed in the so-called notional mortality account. This amount is then shared among those who remained alive at time $t$, as well as those that died within the period $(t, t+d t)$. The crucial point is that in the pooled annuity overlay fund the allocation is proportional to the wealth invested $W_{t}^{k}$ by the individual and his mortality rate $\lambda_{t}^{k}$ at $(t, t+d t)$, i.e., each individual receives the following proportion of the overall amount in the notional mortality account:

$$
\frac{\lambda_{t}^{k} W_{t}^{k}}{\sum_{m=1}^{M} W_{t}^{m} \lambda_{t}^{m} L_{t}^{m}}
$$

where $L_{t}^{m}$ is the number of people alive at time $t$ in subgroup m, i.e., including those that died in $(t, t+d t)$.

Likewise, when we consider a tontine-type product, we assume a group with $n$ participants and $M$ homogeneous subgroups (or as Milevsky and Salisbury (2016) call them: cohorts) each with $n_{i}$ participants so that $\sum n_{i}=n$. The subgroups are homogenous in that their members are of the same age and have the same initial wealth to invest (i.e., at time $t=0$ denoted by 
$W_{0}^{k}$ ). To avoid the actuarial unfairness of the classical tontines, Milevsky and Salisbury (2016) introduce the price per share $\frac{1}{\pi_{i}}$ for a subgroup i. Thus, based on their wealth and other factors such as age (i.e., force of mortality), the individuals in the different subgroups are required to pay a different price per share and, hence, they acquire a different number of shares respectively. The overall payout is determined by the total amount initially invested by the group multiplied by the deterministic payout function $d(t)$ that governs the payout per initial dollar invested. Recall that the payout function $d(t)$ is continuous and so is the payout, i.e., payouts are not only made when an individual dies. As such, the proportion of the overall payout for each living individual is given by the amount of shares held with respect to the sum of the shares of the survivors. This means a known overall amount is paid out to a decreasing number of surviving individuals.

In contrast to the pooled annuity overlay fund proposed by Donnelly et al. (2014), this tontine-like product cannot be actuarially fair. Yet, the explicit structure of this tontine depends on the specification of the payout rate $d(t)$ and the price per share for each subgroup $\frac{1}{\pi_{i}}$. Milevsky and Salisbury (2016) provide necessary and sufficient conditions for the existence of an equitable tontine for a given payout function $d(t)$ (Milevsky and Salisbury, 2016, Theorem 4). This means they provide conditions for share prices to exist so that the tontine is equitable. As they explain, intuitively their theorem states an equivalent condition to the non-existence of equitable share prices: If share prices exist such that a subgroup finds this tontine favourable, even though they only get paid after all individuals from another subgroup have died, then share prices which make this tontine equitable do not exist.

Recall that equitability, unlike actuarial fairness, means that a participant can expect a small actuarial loss, but at least this does not discriminate any subgroup. Milevsky and Salisbury (2016) claim this is an acceptable property in return for having a simple, transparent product with a deterministic payout function. However, note that as participation in a pooled annuity overlay fund can be reconsidered at any moment in time, pensioners therefore also have the freedom to design their own investment decisions, that is, they can reduce the investment amount in order to obtain the other part as a payout. In other words, members can join or exit the pool as they wish, and they can also reconsider their reinvestment decisions and, so, reduce a proportion of their wealth according to a certain payout structure,

Let's consider a number of different examples of tontines as presented in Milevsky and Salisbury (2016). First, consider the so-called proportional tontine. Here, the price per share (for each subgroup) equals the price that an individual in this subgroup has to pay for a standard annuity which pays $1 \$$ for the rest of his life. Further, the payout function $d(t)$ is proportional to the mean number of surviving tontine shares. This tontine is only equitable in the limit, i.e., for an infinitely sized group. Also, it is optimal in the limit as shown in Milevsky and Salisbury (2016, Theorem 6). This means that (for a strictly concave utility function) the utility of each subgroup is optimized simultaneously.

A generalisation of the proportional tontine is the so-called natural tontine where the payout function has to be proportional to the mean number of surviving tontine shares, but no specification about the share prices are made. They are referred to as 'natural' by Milevsky and Salisbury (2016) because it seems a natural requirement to the payout function to have this proportionality. The natural tontine equals the proportional tontine in the limit (and thus is asymptotically optimal). To have not only natural but also, as desired, equitable tontines, we have to compute simultaneously share prices $\frac{1}{\pi_{i}}$ for each subgroup $i$ and the payout function 
$d(t)$. This problem can be a computational challenge in practice. As mentioned, there exist necessary and sufficient conditions with regard to a tontine for the existence of equitable prices (which are then unique up to a multiplicative constant). But in the case of natural tontines, to date this remains a mere conjecture of Milevsky and Salisbury (2016). This makes proportional tontines, although not equitable, easier to use, at least from a practical point of view. Milevsky and Salisbury (2016, p.18) argue: "Though the theoretical basis of proportional tontines is not as appealing as that of natural ones, they are simpler to compute, and they do appear to perform reasonably well in practice." Thus, they see proportional tontines as "acceptable alternatives" in cases when the computation of a natural equitable tontine is too difficult.

To conclude this section, we provide a summary overview of the differences and similarities of the two products (see Table 1):

Table 1: Comparison of the properties of a pooled annuity overlay fund and an income tontine

\begin{tabular}{|c|c|c|}
\hline & Pooled annuity overlay fund & Income tontine \\
\hline Pool of members & $\begin{array}{l}\text { Open (join and abandon } \\
\text { fund at any time) }\end{array}$ & Closed \\
\hline Timeframe & Variable & Over lifetime only \\
\hline Payout & $\begin{array}{l}\text { Stochastic (only when } \\
\text { member dies) }\end{array}$ & $\begin{array}{l}\text { Deterministic and continuous payout } \\
\text { rate }\end{array}$ \\
\hline $\begin{array}{l}\text { Distribution of } \\
\text { payout }\end{array}$ & $\begin{array}{l}\text { According to wealth and } \\
\text { rate of mortality } \\
\text { Among surviving and } \\
\text { recently deceased members }\end{array}$ & $\begin{array}{l}\text { According to amount of shares } \\
\text { (determined by wealth and share } \\
\text { price) } \\
\text { Among surviving members }\end{array}$ \\
\hline Actuarially fair & Yes & No \\
\hline Equitable & $\begin{array}{l}\text { Yes (given that it is } \\
\text { actuarially fair) }\end{array}$ & $\begin{array}{l}\text { Sufficient and necessary conditions } \\
\text { exist }\end{array}$ \\
\hline $\begin{array}{l}\text { Entity guaranteeing } \\
\text { a fixed income for } \\
\text { life }\end{array}$ & Does not exist & Does not exist \\
\hline
\end{tabular}

\section{A general framework}

A comparison of the characteristics of the two products is of obvious interest to the sector and should shed provide us with a more complete understanding of them. To be able to compare a pooled annuity overlay fund and an equitable tontine, we first have to modify the redistribution of wealth in the former so that it is only redistributed among surviving members.

The way to achieve this can be outlined as follows. For a given instant of time $(t, t+d t)$, we assume that the k-th person died within this time interval and that his wealth $W_{t}^{k}$ is to be redistributed (recall that in the standard setting a certain fraction is withheld for the bequest of the deceased). We wish to find the factor $\left(1+A_{t}^{k}\right)$ by which we have to increase the wealth $W_{t}^{k}$ of this person so that the amount redistributed among all surviving members is exactly equal to the initial wealth $W_{t}^{k}$ of the k-th person. In other words, the new total amount $\left(1+A_{t}^{k}\right) W_{t}^{k}$ minus the proportion corresponding to the deceased member must equal the 
initial amount $W_{t}^{k}$. As we are unable to determine in advance the subgroup in which a member will die, we need to impose this condition for all subgroups $k=1, \ldots, M$. As such, the following formula should hold:

$$
W_{t}^{k}\left(1+A_{t}^{k}\right)-W_{t}^{k}\left(1+A_{t}^{k}\right) \frac{\lambda_{t}^{k} W_{t}^{k}\left(1+A_{t}^{k}\right)}{\sum_{m=1}^{M} W_{t}^{m} \lambda_{t}^{m} L_{t}^{m}\left(1+A_{t}^{m}\right)}=W_{t}^{k}, \text { for } k=1, \ldots, M
$$

This can be rewritten as:

$$
A_{t}^{k}=\frac{\lambda_{t}^{k} W_{t}^{k}\left(1+A_{t}^{k}\right)}{\sum_{m=1}^{M} W_{t}^{m} \lambda_{t}^{m} L_{t}^{m}\left(1+A_{t}^{m}\right)-\lambda_{t}^{k} W_{t}^{k}\left(1+A_{t}^{k}\right)}, \quad \text { for } k=1, \ldots, M
$$

In equation (2), the denominator consists of the sum (according to the mortality rate) of the weighted wealth of the members alive at time $t+d t$, i.e., all except the $\mathrm{k}$-th person. To compute the $A_{t}^{k}$, we fix a starting value $A_{t}^{k, 0}$ and propose an iterative procedure to determine the final value:

$$
\begin{gathered}
A_{t}^{k, 0}=\frac{\lambda_{t}^{k} W_{t}^{k}}{\sum_{m=1}^{M} W_{t}^{m} \lambda_{t}^{m} L_{t}^{m}-\lambda_{t}^{k} W_{t}^{k}}, \\
A_{t}^{k, h}=\frac{\lambda_{t+d t}^{k} W_{t}^{k}\left(1+A_{t}^{k, h-1}\right)}{\sum_{m=1}^{M} W_{t}^{m} \lambda_{t}^{m} L_{t}^{m}\left(1+A_{t}^{m, h-1}\right)-\lambda_{t}^{k} W_{t}^{k}\left(1+A_{t}^{k, h-1}\right)},
\end{gathered}
$$

for a positive natural number $\mathrm{h}$, indicating the iterations.

By using this procedure, we can ensure that the entire wealth of the deceased $W_{t}^{k}$ is redistributed among the surviving members. Thus, instead of considering the pooled annuity overlay fund with initial wealth $W_{t}^{k}$ for $k=1, \ldots, M$, we consider the pooled annuity overlay fund with initial wealth $W_{t}^{k}\left(1+A_{t}^{k}\right)$ for each $k=1, \ldots, M$. Then, equation (1) ensures that the wealth of the deceased $W_{t}^{k}$ is redistributed among the surviving members.

From a technical point of view, this solution is viable only if one member dies at the given instant in time. In practice, if more than one member dies during the time interval considered (e.g., a day), the algorithm would have to be applied separately and consecutively, ordering the deaths by descending age of the deceased.

\section{Illustration}

We are now in a position to compare the actuarial mechanisms of the pooled annuity overlay fund (Donnelly et al., 2014) and the equitable scheme (Milevsky and Salisbury, 2016) by considering a simple example. While the setup for the pooled annuity overlay fund is fully specified, we need more precise details regarding the tontine being used. By selecting the payout function $d(t)$ and the price per share $\frac{1}{\pi_{i}}$ for each subgroup, we can fully specify the Milevsky and Salisbury (2016) tontine and determine if it is equitable or not. As discussed above, Milevsky and Salisbury (2016) recognised that a proportional tontine can be considered instead of a natural and equitable one and it will "perform reasonably well in practice". So, for the sake of simplicity, we consider a proportional tontine. 
Imagine a single man with an initial wealth of $100 \$$, aged 65 and a mortality rate of 0.99 . He wishes to join a homogeneous pool of 99 people (i.e., $\mathrm{n}=100$ ) also aged 65 , with the same mortality rate (i.e., 0.99) and who each have an initial wealth of $10 \$$. For the sake of simplicity, we assume the risk-free interest rate to be $r=0 \%$ (we thereby avoid the effect of returns resulting from investing wealth with fixed returns).

To illustrate a cumulative payout, we consider different instants in time (1, 5, 10, 20 and 30 years). For these instants, we examine different cases: first, we consider the payout in the case that none of the members dies. Second, we consider likely outcomes in a cohort of 65-yearolds (although of course these can be accommodated to other situations). Here, we consider one death after one year, two deaths after five years, five deaths after ten years, eleven deaths after twenty years and thirty deaths after thirty years. We also consider highly unlikely outcomes for a cohort purchasing an annuity tontine at the age of 65 . Hence, we consider five deaths after one year, ten deaths after five years, twenty-five deaths after ten years, fifty deaths after twenty years and ninety deaths after thirty years, which would be considerably more deaths than any reasonable mortality table would indicate for a modern society.

Table 2 records the cumulative payout for the single person (with $100 \$$ initial wealth) and Table 3 shows the cumulative payout for the other investors (with $10 \$$ initial wealth) in the case that they survive.

\section{Calculating the cumulative payouts}

As discussed, two choices have to be made concerning the tontine: namely, the payout function $d(t)$ and the price per share $\frac{1}{\pi_{i}}$ for each subgroup. In a proportional tontine, the price per share equals the price that has to be paid to obtain a standard annuity of $1 \$$ for life. As we know, this price depends on the age of the members in the corresponding subgroup. Given that in our example all the participants are of the same age (in both subgroups), the price per share $\frac{1}{\pi_{i}}$ is the same for all participants $(15.02 \$)$. Note that we have used the Society of Actuaries' (2008) mortality table available in R package lifecontingencies (Spedicato, 2013).

In a proportional tontine, the payout function $d(t)$ (per initial dollar of investment) is a weighted sum of the annuity factors (the inverse of the price for the standard annuity of $1 \$$ per life) for each subgroup. Given that in our example the prices were the same across all subgroups, the payout function $d(t)$ at time $t$ simplifies to the product of the survival function for a 65-year-old individual surviving $t$ years, ${ }_{t} p_{65}$, and the annuity factor for a 65 -year-old, $\frac{1}{a_{65}}$ where $a_{65}$ is the price for a standard annuity of $1 \$$ for life for a 65 -year-old:

$$
d(t)={ }_{t} p_{65} * \frac{1}{a_{65}}
$$

For example, the payout rate after one year is $d(1)=0.978 * \frac{1}{15.02}=0.065$ per initial dollar invested. Then, the overall payout at one year is the initial total wealth multiplied by the payout rate: $d(1) *(1 * 100+99 * 10)=71.01$.

This amount is redistributed among the surviving participants according to the shares held. As the share prices are equal in both subgroups, this is equivalent to a distribution made according to the proportion of the initial investment made. 
If no one dies, the single man with the greatest initial wealth would receive $\frac{100}{100+99 * 10}=$ $9.17 \%$ of the total payout, and each of the other participants would receive $\frac{10}{100+99 * 10}=$ $0.92 \%$, i.e., as the former invested ten times more than the latter, he would likewise receive ten times more. Multiplying these percentages with the overall payout we obtain the first number in the first rows of Tables 2 and 3, respectively.

If a member dies, the same overall amount is distributed among all surviving members according to the remaining shares. Note that which person dies makes a difference.

If the single man with the greatest initial wealth (i.e., 100\$) dies, the overall amount paid out after 1 year, 71.01\$, is redistributed equally among the remaining 99 members people (given that they all made the same initial investment), i.e., $71.01 \$: 99=0.717$ which equals $7.17 \%$ of their initial investment of $10 \$$ (see the first value in the fourth row of Table 2).

If, on the other hand, one of the members with a $10 \$$ initial investment dies, the percentages change only slightly (in comparison to the scenario in which all the members survive). Thus, the single man with the greatest initial wealth would receive $\frac{100}{100+98 * 10}=9.26 \%$ and each of the other survivors would receive $\frac{10}{100+98 * 10}=0.93 \%$. Accordingly, the difference between the first and second values in the second column of each table is not very great.

Table 2: Cumulative payout (as a percentage of capital invested) over the years for the wealthy investor (initial wealth of 100\$) for a proportional tontine assuming Society of Actuaries' mortality table to calculate price per share and all the wealth invested at the outset to buy shares.

\begin{tabular}{|c|c|c|c|c|c|}
\hline \multirow[b]{2}{*}{ Events } & \multicolumn{5}{|c|}{ Time } \\
\hline & In 1 year & In 5 years & In 10 years & In 20 years & In 30 years \\
\hline No death & 6.52 & 30.96 & 57.06 & 90.18 & 99.45 \\
\hline $\begin{array}{l}\text { Likely event } \\
\text { ( } 1 \text { death in one year, } 2 \text { deaths } \\
\text { in } 5 \text { years, etc.) and the } \\
\text { wealthy investor does not die }\end{array}$ & 6.58 & 31.06 & 57.29 & 90.42 & 99.55 \\
\hline $\begin{array}{l}\text { Likely event } \\
\text { ( } 1 \text { death in one year, } 2 \text { deaths } \\
\text { in } 5 \text { years, etc.) and one of } \\
\text { the deceased is the wealthy } \\
\text { investor }\end{array}$ & 0 & 25.11 & 52.29 & 88.10 & 99.19 \\
\hline $\begin{array}{l}\text { Highly unlikely event } \\
\text { ( } 5 \text { deaths in one year, } 10 \\
\text { deaths in } 5 \text { years, etc.) and } \\
\text { the wealthy investor does not } \\
\text { die }\end{array}$ & 6.83 & 31.55 & 58.48 & 91.95 & 100.70 \\
\hline $\begin{array}{l}\text { Highly unlikely event } \\
\text { ( } 1 \text { death in one year, } 2 \text { deaths } \\
\text { in } 5 \text { years, etc.) and one of } \\
\text { the deceased is the wealthy } \\
\text { investor }\end{array}$ & 0 & 25.11 & 52.29 & 88.10 & 99.19 \\
\hline
\end{tabular}


Table 3: Cumulative payout (as a percentage of capital invested) over the years for a $10 \$$ initial investor for a proportional tontine assuming Society of Actuaries' mortality table to calculate price per share and all the wealth invested at the outset to buy shares.

\begin{tabular}{|c|c|c|c|c|c|}
\hline \multirow[b]{2}{*}{ Events } & \multicolumn{5}{|c|}{ Time } \\
\hline & In 1 year & In 5 years & In 10 years & In 20 years & In 30 years \\
\hline No death & 6.52 & 30.96 & 57.06 & 90.18 & 99.45 \\
\hline $\begin{array}{l}\text { Likely event } \\
\text { ( } 1 \text { death in one year, } 2 \text { deaths } \\
\text { in } 5 \text { years, etc.) and the } \\
\text { wealthy investor does not die }\end{array}$ & 6.58 & 31.06 & 57.29 & 90.42 & 99.55 \\
\hline $\begin{array}{l}\text { Likely event } \\
\text { (1 death in one year, } 2 \text { deaths } \\
\text { in } 5 \text { years, etc.) and one of } \\
\text { the deceased is the wealthy } \\
\text { investor }\end{array}$ & 7.17 & 31.61 & 57.76 & 90.65 & 99.60 \\
\hline $\begin{array}{l}\text { Highly unlikely event } \\
(5 \text { deaths in one year, } 10 \\
\text { deaths in } 5 \text { years, etc.) and } \\
\text { the wealthy investor does not } \\
\text { die }\end{array}$ & 6.83 & 31.55 & 58.48 & 91.95 & 100.70 \\
\hline $\begin{array}{l}\text { Highly unlikely event } \\
\text { (1 death in one year, } 2 \text { deaths } \\
\text { in } 5 \text { years, etc.) and one of } \\
\text { the deceased is the wealthy } \\
\text { investor }\end{array}$ & 7.48 & 32.19 & 59.22 & 92.64 & 102.06 \\
\hline
\end{tabular}

Both tables show that even after thirty years the initial investment of $100 \$$ or $10 \$$, respectively, has not been paid back (except in the case of the highly unlikely events after thirty years). It should be recalled that in the income tontine plan all members have to remain in the scheme, whereas in the case of the pooled annuity overlay fund participants are free to leave as and when they wish. This means that after an initial investment (let's say $100 \$$ ) in the pooled fund, a member can withdraw the exact same amount of wealth from it as he would receive as a payout from the proportional tontine (which is then accumulated in Tables 2 and 3). Hence, one could replicate exactly the tontine payout structure and still have an amount left to further invest in the pooled annuity overlay fund.

\section{Conclusions}

We have analysed two new products - pooled funds as proposed by Donnelly et al. (2014) and income tontines as outlined by Milevsky and Salisbury (2016) - that pool longevity risk among participants. In line with Weinert and Grundl (2016), we feel there exist appropriate incentives for individuals to hold some fraction of their retirement wealth in these contemporary tontine products as opposed to the complete annuitization of their wealth. Yet, having said that, Weinert and Grundl's (2016) analysis of consumer spending (drawing on data from the German Socio-Economic Panel Study, 1984-2013) shows that an old-age liquidity-need function is concave and increasing with age. However, the requirements and circumstances of each pensioner make these budget needs highly specific and extremely difficult to specify in advance. As such, the possibilities of investment and participation provided by the pooled annuity overlay fund appear to be especially valuable, since they allow participants to adopt personalized strategies and to modify them in the de-accumulation phase, something that a predefined annuity fails to do. 
The recent increase in published studies addressing this subject is indicative of the interest in pension insurance in a very broad sense in all countries. To mention just a few, Huang and Milevsky (2016) analyse the retirement consumption problem with differentially taxed accounts of retirees, showing how Canadians de-accumulate financial wealth during retirement. Huang et al. (2016) turn their focus on optimal purchasing of deferred income annuities. The authors assume a mean-reverting model for payout yields and show that a riskneutral consumer who wishes to maximize his expected retirement income should wait until yields reach a threshold (which lies above historical averages) and then purchase the deferred income annuity in one lump sum. Denuit et al. (2015) propose that the length of the deferment period could be subject to revision, providing longevity-contingent deferred life annuities and allowing for a dynamic decision process over time rather than having to make a choice immediately on retirement. Mikevsky and Salisbury (2015), in presenting optimal retirement income tontines, rekindle a debate about retirement income products that has long been neglected, and provide the mathematical finance tools to design the next generation of tontine annuities. Yet, note that Donnelly (2015) insists that actuarial unfairness cannot be referred to as solidarity given that there is no uncertainty as to who bears the expected losses resulting from the actuarial unfairness. She also examines other schemes, including the group selfannuitization scheme proposed by Piggott et al. (2005) for any heterogeneous group of members which is not actuarially fair. In short, all these studies appear to be inspiring private pension providers to innovate and, we believe, they will be highly influential in the way longevity risk management will be addressed in the near future.

It is self-evident that modern tontines and pooled funds can reduce both the insurer's capital requirements and the safety loadings included in annuity prices, but just how substantial these reductions might be needs to be clarified by further research, since they will depend greatly on the marketing and uptake of these new products. In their study of enhanced annuities, Gatzert and Klotzki (2016) indicate that modern tontines and pooled funds are likely to come up against notable obstacles in the future, given consumers' insufficient familiarity with the product, continuing hesitation on the part of distributors, and the general absence of interest among consumers for a lifelong annuity, which is in line with their underestimation of their own life expectancy.

\section{Acknowledgements}

\section{We thank the Spanish Ministry of Economy FEDEF grant ECO2013-48326-C2-1-P and} ICREA Academia.

\section{References}

Chan, W. S., Li, J. S., Zhou, K. Q., \& Zhou, R. (2016). Towards a Large and Liquid Longevity Market: A Graphical Population Basis Risk Metric. The Geneva Papers on Risk and Insurance - Issues and Practice, 41(1), 118-127.

Denuit, M., Haberman, S., \& Renshaw, A. E. (2015). Longevity-contingent deferred life annuities. Journal of Pension Economics and Finance, 14(03), 315-327.

Donnelly, C. (2015). Actuarial fairness and solidarity in pooled annuity funds. Astin Bulletin, 45(01), 49-74.

Donnelly, C., Guillén, M., \& Nielsen, J. P. (2013). Exchanging uncertain mortality for a cost. Insurance: Mathematics and Economics, 52, 65-76.

Donnelly, C., Guillén, M., \& Nielsen, J. P. (2014). Bringing cost transparency to the life annuity market. Insurance: Mathematics and Economics, 56, 14-27.

Gatzert, N., \& Klotzki, U. (2016). Enhanced Annuities: Drivers of and Barriers to Supply and Demand. The Geneva Papers on Risk and Insurance - Issues and Practice, 41(1), 53-77. 
Huang, H., \& Milevsky, M. A. (2016). Longevity risk and retirement income tax efficiency: A location spending rate puzzle. Insurance: Mathematics and Economics, accepted.

Huang, H., Milevsky, M. A., \& Young, V. R. (2016). Optimal Purchasing of Deferred Income Annuities When Payout Yields are Mean-Reverting. Review of Finance, 1-35.

Lin, Y., \& Cox, S. H. (2005). Securitization of mortality risks in life annuities. Journal of Risk and Insurance, $72(2), 227-252$

Lusardi, A., \& Mitchell, O. S. (2007). Baby boomer retirement security: The roles of planning, financial literacy, and housing wealth. Journal of Monetary Economics, 54(1), 205-224.

Milevsky, M. (2015). King William's tontine: why the retirement annuity of the future should resemble its past. Cambridge University Press.

Milevsky, M. A., \& Salisbury, T. S. (2015). Optimal retirement income tontines. Insurance: Mathematics and Economics, 64, 91-105.

Piggott, J., Valdez, E. A., \& Detzel, B. (2005). The simple analytics of a pooled annuity fund. Journal of Risk and Insurance, 72(3), 497-520.

Spedicato, G.A. (2013). The lifecontingencies Package: Performing Financial and Actuarial Mathematics Calculations in R. Journal of Statistical Software, 55(10), 1-36. URL http://www.jstatsoft.org/v55/110/.

Stamos, M. Z. (2008). Optimal consumption and portfolio choice for pooled annuity funds. Insurance: Mathematics and Economics, 43(1), 56-68.

Weinert, J. H., \& Gründl, H. (2016). The modern tontine: An innovative instrument for longevity risk management in an aging society (No. 22/16). ICIR Working Paper Series. 